\title{
ELECTRICAL PROPERTIES OF RF SPUTTERED NiCr THIN FILM RESISTORS WITH Cu CONTACTS
}

\author{
R.K. NAHAR and N.M. DEVASHRAYEE \\ Central Electronics Engineering Research Institute, Pilani (Rajasthan) 333031 India
}

(in final form June 3, 1982)

Investigations on $\mathrm{RF}$ sputtered $\mathrm{NiCr}$ thin film resistors, fabricated using $\mathrm{Cu}$ as conductor metallization, were made. The contact resistance characteristics, resistor film characteristics and TCR of the resistors were measured. The effect of heat treatment on the resistor characteristics was studied. A suitable annealing cycle for the resistor stabilization was studied. A suitable annealing cycle for the resistor stabilization was obtained. The effect of passivation by a thin quartz film on the resistor properties was also examined. The results are presented and discussed in this paper.

\section{INTRODUCTION}

$\mathrm{NiCr}$ is one of the most commonly used resistive material for fabricating precision thin film resistors. This transition metal alloy exhibits a wide range of resistivity, low temperature coefficient of resistance (TCR) and high stability of electrical properties. Owing to its technological importance $\mathrm{NiCr}$ resistors have been the subject of several investigations. Numerous publications on different aspects of resistor fabrication and characterization have appeared in the literature during the past fifteen years. ${ }^{1-19}$

Conventionally a multilayer Ti-Pd-Au conductor system is used as the contact metallization for NiCr resistors. ${ }^{11}$ In recent years due to increased cost of the precious metals a need for a low cost replacement metallization for the expensive Ti-Pd-Au has been realized. Different metals ${ }^{10,15}$ and metal combinations ${ }^{16,17}$ have been investigated for the purpose. We have examined the use of copper as the contact metallization. Copper has a higher conductivity and is less expensive compared to gold. Also, copper is easily solderable. The limitation on using $\mathrm{Cu}$ for contact metallization is that the $\mathrm{Cu} / \mathrm{NiCr}$ contact cannot be annealed at the high temperature, usually required for resistor stabilization, due to oxidation of $\mathrm{Cu}$ and interdiffusion of $\mathrm{Cr}$ into $\mathrm{Cu} .{ }^{18}$

The purpose of this paper is to report the results of our investigation on $\mathrm{NiCr}$ resistors fabricated with $\mathrm{Cu}$ contacts. The contact resistance was measured. The effect of heat treatment on the contact characteristics was studied. An optimum thermal annealing cycle for the resistors stabilization was obtained. The resistor characteristics and TCR of the resistors measured before and after the heat treatment are presented. The effect of passivation by a thin quartz film on the resistor properties is also reported in this paper.

\section{EXPERIMENTAL}

The resistors were fabricated on Alsimag glazed ceramic substrates. The substrates were cleaned by the standard procedure and were dried by blowing nitrogen gas before loading onto a water cooled anode in the sputtering chamber. An $8620 \mathrm{~J}$ rf sputtering machine of MRC was employed to sputter the resistor $(\mathrm{NiCr})$ and the conductor $(\mathrm{Cu})$ films. The composition of the $\mathrm{NiCr}$ target purchased from MRC was stated to be $\mathrm{Ni40/Cr60}$. The procedure adopted for the films deposition was as follows:

The sputtering chamber was first evacuated to a pressure of $8 \times 10^{-7}$ torr. Then UHP argon gas was introduced in the chamber through a needle valve. The pressure inside the 
TABLE I

Typical $\mathrm{NiCr} / \mathrm{Cu}$ film deposition parameters:

\begin{tabular}{ll}
\hline Substrate & Glazed Ceramic \\
Sputtering gas & UHP Argon \\
Argon Pressure during sputtering. & $5 \mathrm{~m}$ torr. \\
Distance between target and the substrate holder. & $7 \mathrm{~cm}$. \\
NiCr target composition & $\mathrm{Ni} 40 / \mathrm{Cr} 60$ \\
NiCr sputtering voltage & $2 \mathrm{KV}$. \\
$\quad$ sputtering time & $3 \mathrm{~min}$. \\
Cu sputtering voltage & $1.5 \mathrm{KV}$. \\
$\quad$ sputtering time & $60 \mathrm{~min}$. \\
Quartz sputtering voltage & $1.5 \mathrm{KV}$. \\
\multicolumn{1}{c}{ sputtering time } & $30 \mathrm{~min}$. \\
\hline
\end{tabular}

chamber was maintained at $5 \mathrm{~m}$ torr and the chamber was evacuated, in this state, for 15 minutes to ensure an inert atmosphere in the sputtering chamber. Both the $\mathrm{NiCr}$ and $\mathrm{Cu}$ targets were presputtered separately for 20 minutes each at a target voltage higher than the actual sputtering voltage. The $\mathrm{NiCr}$ and $\mathrm{Cu}$ films were sputtered sequentially in the same pump-down. Typical data of the sputtering process are given in Table I. The sheet resistivity of the $\mathrm{NiCr}$ film was $200 \mathrm{Ohms} / \mathrm{square}$ and thickness of the $\mathrm{Cu}$ film was 1.5 microns.

The resistor and conductor patterns were delineated by selectively etching the $\mathrm{Cu}$ and $\mathrm{NiCr}$ films using a photolithography technique. The copper contacts were protected by $\mathrm{Sn} \mathrm{Pb} 60 / 40$ solder immediately after fabrication. Measurements were taken on the as prepared resistors, after heat treatment of the resistors and after depositing a thin quartz film ( 0.3 microns) on the resistors.

\section{RESULTS AND DISCUSSION}

\subsection{Contact Resistance Characteristics.}

The contact resistance of the $\mathrm{Cu}-\mathrm{NiCr}$ contact was measured by a simple bridge balance technique. ${ }^{19}$ The electrical equivalent circuit of the measuring system is shown in Figure 1(a). It consists of two symmetrical parts. $R_{1}$ and $R_{2}$ are the resistances of the $\mathrm{NiCr}$ resistors, which are nearly equal in value, and $R_{A}, R_{B}$ and $R_{C}$ are the resistances of the contacts $A, B$ and $C$ respectively, as shown in Figure $1(b) . R_{p}, R_{q}$ and $R_{x}, R_{y}$ are the resistances of the potentiometers used to control the voltage drop in the circuit. $E_{1}$ and $E_{2}$ are the potentials of the power supplies. $R_{v}$ is a fixed resistance and a d.c. microvoltmeter is employed to detect the null position.

In the method used, a source of potential $E_{1}$ is connected to provide a current $i_{1}$ between points $A$ and $B$. The compensation current $i_{1}^{\prime}$, between $B$ and $C$ is provided by the source of potential $E_{2}$. After compensation i.e. for a given $E_{1}$ adjusting $E_{2}$ such that $i_{1}=0$, the voltage drop $V_{p}$ will clearly be given by

$$
V_{p}=i_{1}^{\prime}, R_{B}
$$

By measuring $i_{1}{ }^{\prime}$ and $V_{p}$, the contact resistance $R_{B}$ of the contact $B$ can be calculated. Similarly the resistance of the other contacts can be measured.

Employing this technique the current - voltage characteristics of the contacts was measured at room temperature $\left(25^{\circ} \mathrm{C}\right)$ after heating the resistors for an hour at different temperatures ranging from $25^{\circ} \mathrm{C}$ to $225^{\circ} \mathrm{C}$. A representative plot of the characteristics is 


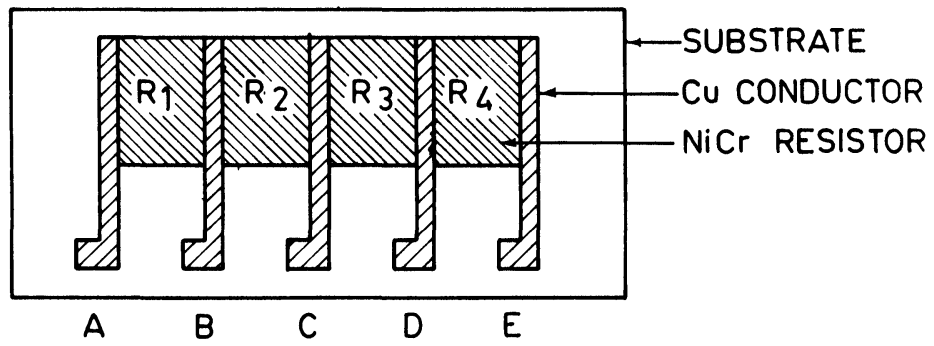

(a)

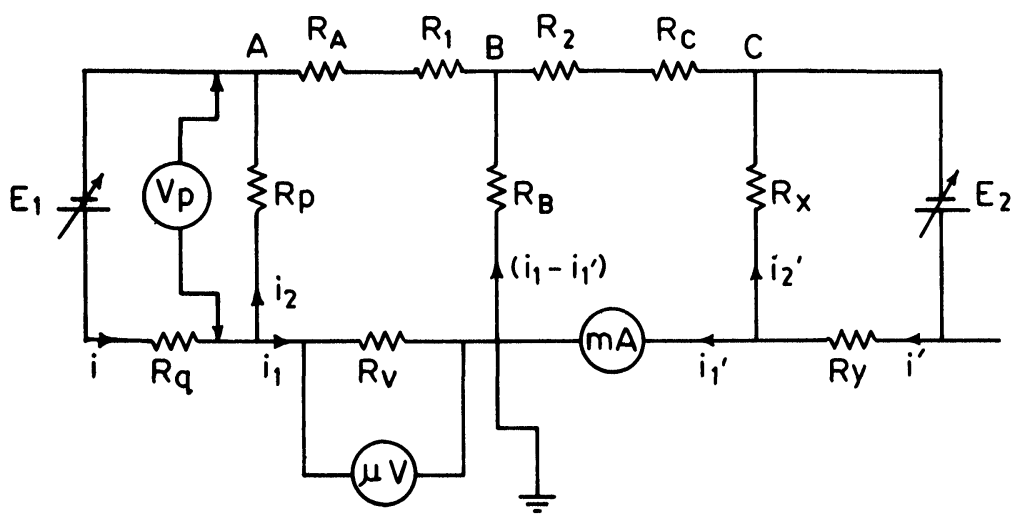

(b)

FIGURE 1 Measurement of contact resistance: (a) the fabricated structure of the NiCr resistors with copper contacts; (b) the electrical circuit.

given in Figure 2. The nature of the characteristics reveal that the $\mathrm{Cu}-\mathrm{NiCr}$ contact is ohmic in the entire range of measurement. The contact resistances of the as prepared resistors is within $2-3 \mathrm{~m} \mathrm{Ohm} \mathrm{cm}^{2}$ This value increases only marginally, as shown in the figure, when the temperature of the resistor is raised from $25^{\circ} \mathrm{C}$ to $200^{\circ} \mathrm{C}$. At $225^{\circ} \mathrm{C}$ although the contact I-V characteristics as shown in the figure remain ohmic, the contact resistance increases drastically. It is at this temperature that we believe the interdiffusion of $\mathrm{Cr}$ into $\mathrm{Cu}$ is substantial. There is also a possibility of some copper film being dissolved in the $\mathrm{Sn} / \mathrm{Pb}$ solder. ${ }^{20}$ The increase in the contact resistance is about 7 times the value obtained after annealing at $200^{\circ} \mathrm{C}$.

In the light of the above results we decided on $150^{\circ} \mathrm{C}$ as a safe annealing temperature for the $\mathrm{Cu}$ contacts protected by $\mathrm{Sn} / \mathrm{Pb}$ solder. That the $150^{\circ} \mathrm{C}$ temperature would be safe for annealing is evident by the phase diagram ${ }^{21}$ of $\mathrm{Cr}-\mathrm{Cu}$ and $\mathrm{Ni}-\mathrm{Cu}$. Any possibility of interdiffusion at this temperature would be negligible. Further the heat treatment at $150^{\circ} \mathrm{C}$ in air rather than at a higher temperature also reduces the possibility of producing an open circuited resistor during the relatively long heat treatment time. ${ }^{4}$

The change in the contact resistance during annealing in air ambient at $150^{\circ} \mathrm{C}$ was measured as a function of time. The data is shown in Figure 3. For comparison the 


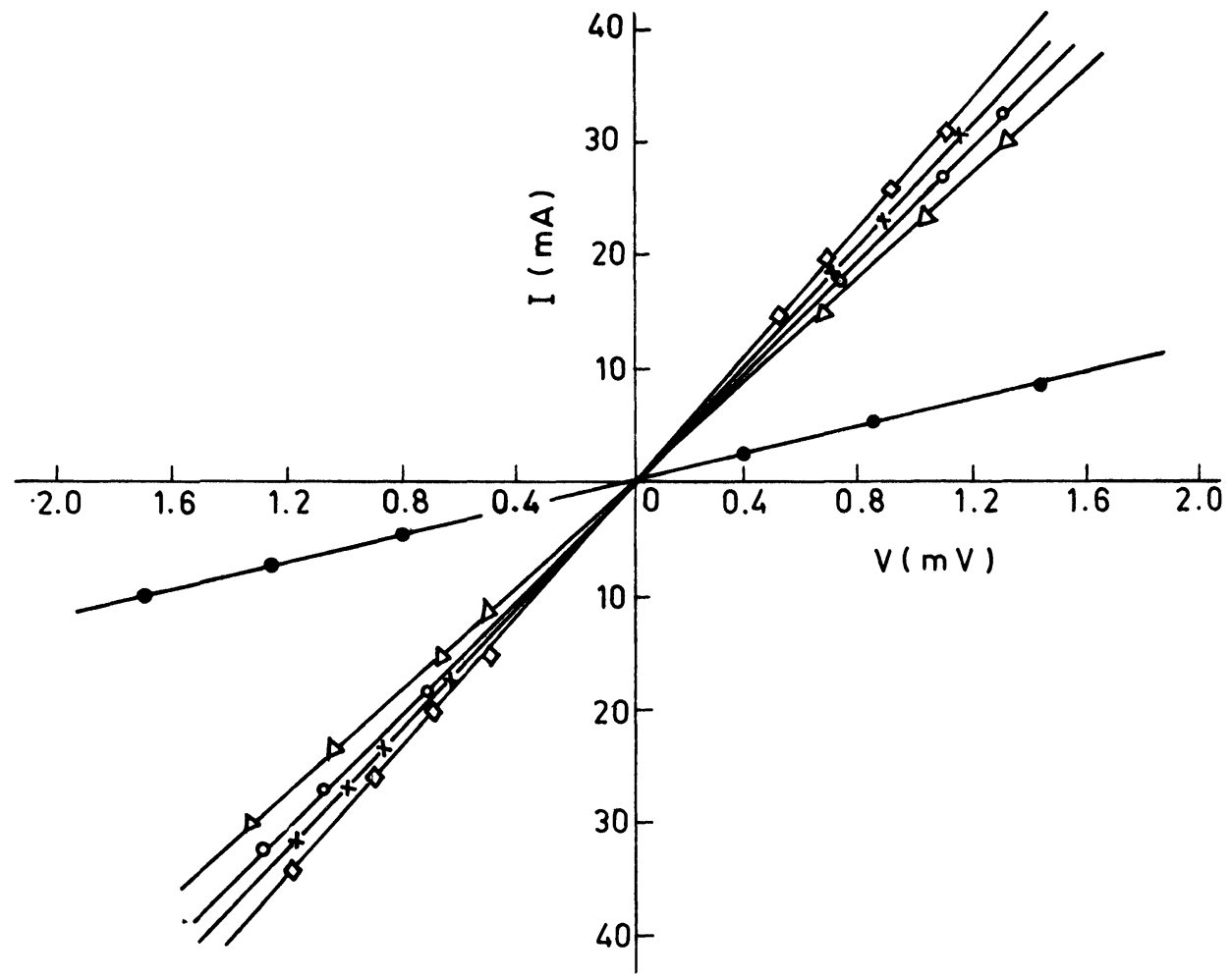

FIGURE 2 The contact I-V characteristics measured at room temperature: ( $\square$ ) before annealing; and after annealing for 1 hour $(\mathrm{X})$ at $75^{\circ} \mathrm{C},(\circ)$ at $150^{\circ} \mathrm{C},(\Delta)$ at $200^{\circ} \mathrm{C}$ and $(\bullet)$ at $225^{\circ} \mathrm{C}$.

contact resistance measured at room temperature before and after annealing is also included in the figure. It may be noted that the contact resistance before annealing was about $2.5 \mathrm{~m} \mathrm{Ohm} \mathrm{cm} .^{2}$ This value increased to about $3 \mathrm{~m} \mathrm{Ohm} \mathrm{cm}^{2}$ after annealing for 48 hours at $150^{\circ} \mathrm{C}$.

\subsection{Resistor Film Characteristics.}

Freshly deposited $\mathrm{NiCr}$ films shows a tendency for self annealing. ${ }^{8}$ This results in changes in resistance and TCR of the film. It is therefore necessary to stabilize the film properties. Usually $\mathrm{NiCr}$ films are annealed in air at $300^{\circ} \mathrm{C}$ for 2 hours for stabilization of the resistor film characteristics. The $\mathrm{NiCr}-\mathrm{Cu}$ resistor system, as discussed in the previous section, cannot be annealed at such high temperatures. The film stabilization temperature was therefore restricted to $150^{\circ} \mathrm{C}$.

As the films were being stabilized in an oven at $150^{\circ} \mathrm{C}$, the change in the film resistance was measured as a function of heat treatment time. Figure 4 shows the increase in the film resistance plotted as a function of the square root of the heat treatment time. The variation is linear. The data indicates that the increase in the film resistance is due to surface oxidation of the $\mathrm{NiCr}$ film and is limited by the diffusion mechanism. ${ }^{4}$ It may be remembered here that oxidation of the $\mathrm{NiCr}$ is preferential. Exposure of the film surface produces $\mathrm{Cr}_{2} \mathrm{O}_{3}$ while $\mathrm{Ni}$ remains virtually in the metallic state. ${ }^{13}$ By oxidizing 


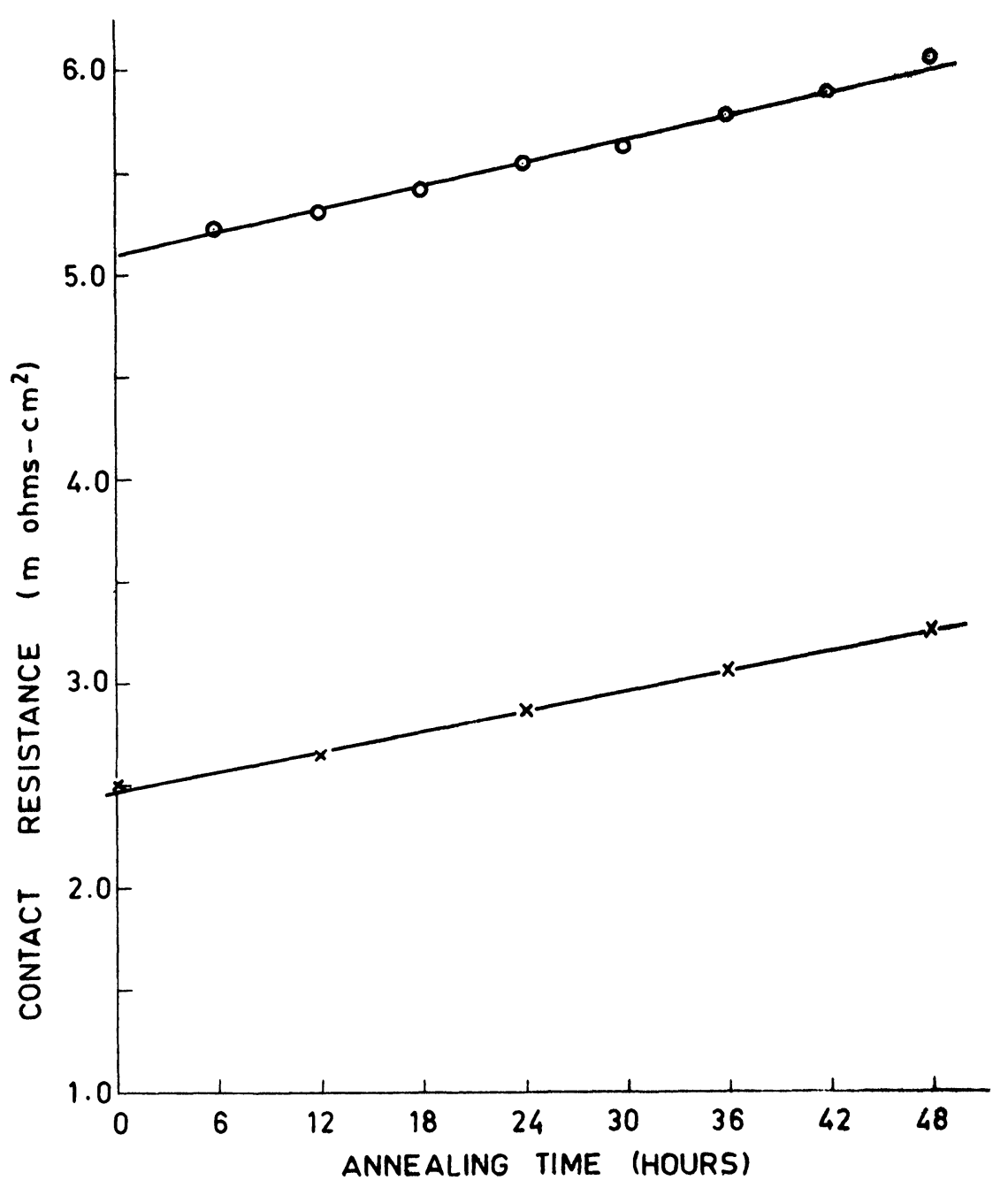

FIGURE 3 The contact resistance measured as a function of annealing time $(\circ)$ at $150^{\circ} \mathrm{C}$ and ( $\mathrm{X}$ ) at room temperature.

the top surface of the film the material beneath is protected against further exposure to the ambient gases, thus stabilizing the films. Typical I-V characteristics of the as prepared resistor, after annealing the resistor and after 1000 hours measured at room temperature, are shown in Figure 5. After stabilization the increase in the film resistance measured on a $51 / 2$ digit HP $3455 \mathrm{~A}$ voltmeter was typically 0.35 percent after 1000 hours at room temperature. This shows that the long term stability of these resistors is not good. We believe that the stabilization by the thermal annealing cycle is not adequate. This was confirmed by depositing a quartz thin film on the heat treated resistors. We observed that the stability improves significantly. A plot of the resistance change measured as a function of time at $70^{\circ} \mathrm{C}$ on these resistors is shown in Figure 6. The stability of these resistors improves from 0.35 percentage to 0.04 percentage. 


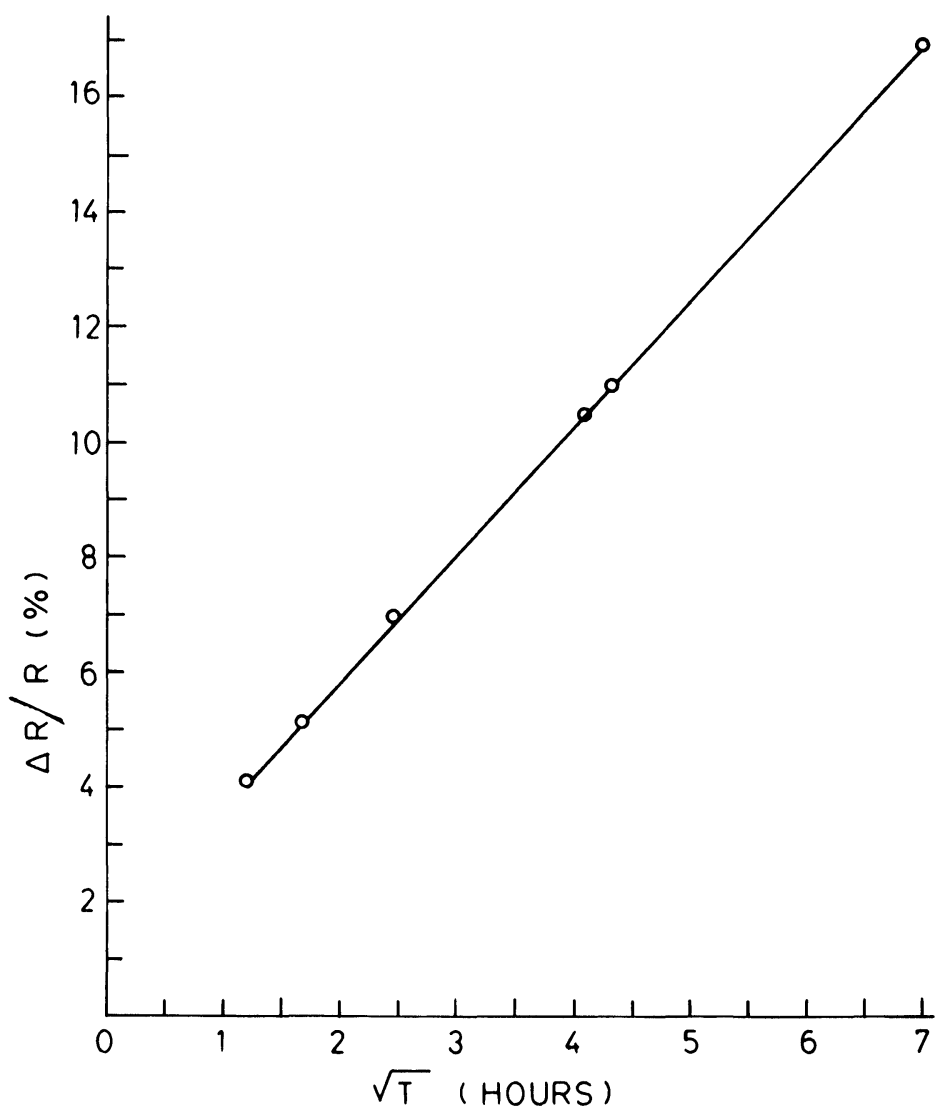

FIGURE 4 The change in the $\mathrm{NiCr}$ film resistance at $150^{\circ} \mathrm{C}$ as a function of square root of the annealing time.

\subsection{Temperature Coefficient of Resistance:}

TCR of the resistors was measured in the temperature range of $25^{\circ} \mathrm{C}$ to $125^{\circ} \mathrm{C}$. Typically the TCR of the resistors after annealing was $25 \mathrm{ppm} /{ }^{\circ} \mathrm{C}$. TCR of the resistors measured as a function of annealing time is given in Figure 7.

\section{CONCLUSIONS}

The results of our investigation show that it is possible to produce good $\mathrm{NiCr}$ resistors using $\mathrm{Cu}$ as a conductor with stable electrical properties.

The contact between the conductor $\mathrm{Cu}$ film and the resistive $\mathrm{NiCr}$ film is ohmic. The contact resistance is $2-3 \mathrm{~m} \mathrm{Ohm} \mathrm{cm}{ }^{2}$ The contact I-V characteristics studied as a function of temperature show that above $200^{\circ} \mathrm{C}$ the contact resistance increases drastically.

The resistor stabilization cycle, decided on the basis of the experimental data, for the $\mathrm{NiCr}$ resistors with $\mathrm{Cu}$ contacts is to anneal at $150^{\circ} \mathrm{C}$ in ambient air for 48 hours. This cycle was found to be safe but the stability of the resistors was not good. The stability 


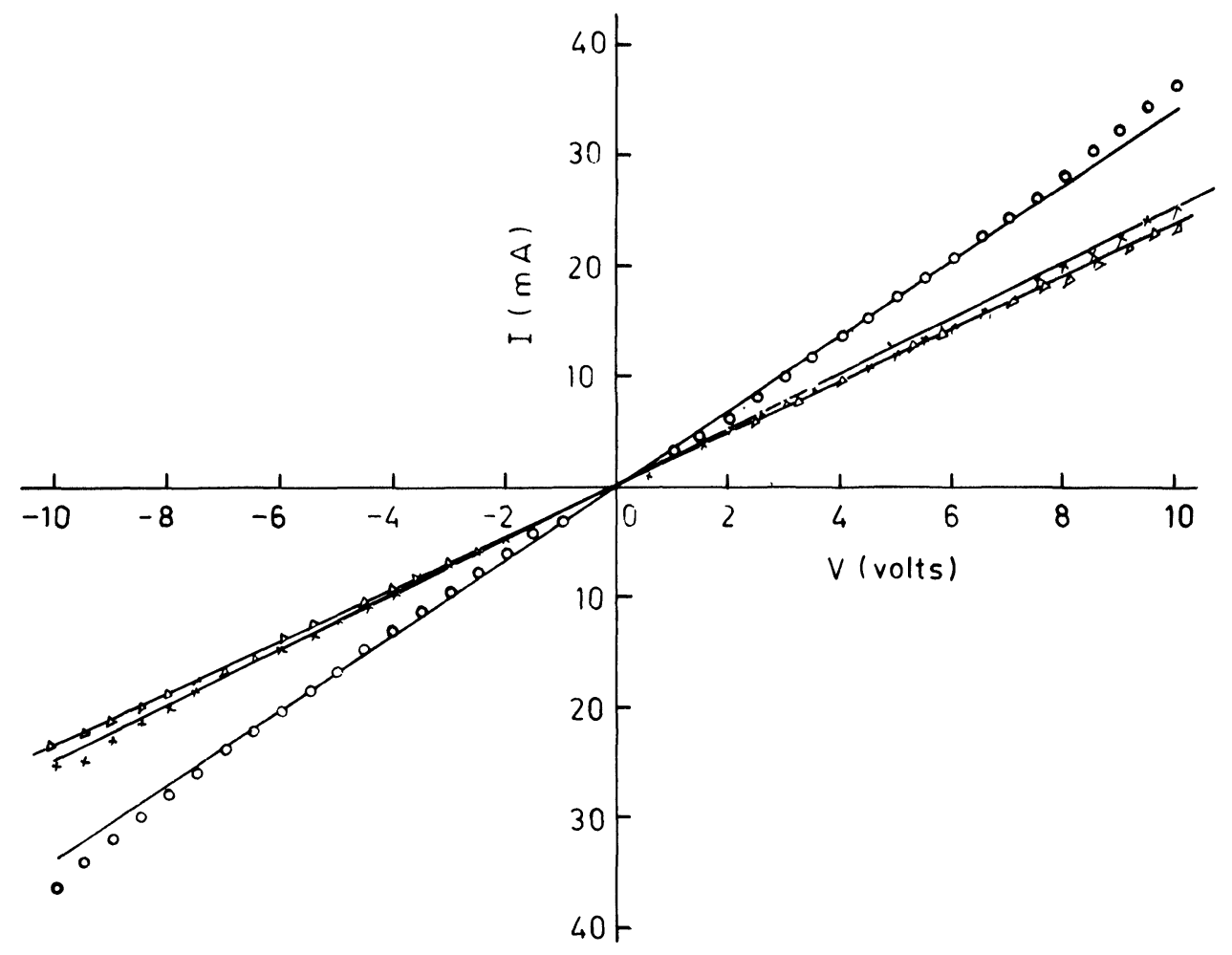

FIGURE 5 Current - voltage characteristics of the resistors: $(0)$ as prepared, $(X)$ after annealing and $(\Delta)$ after 1000 hours at room temperature.

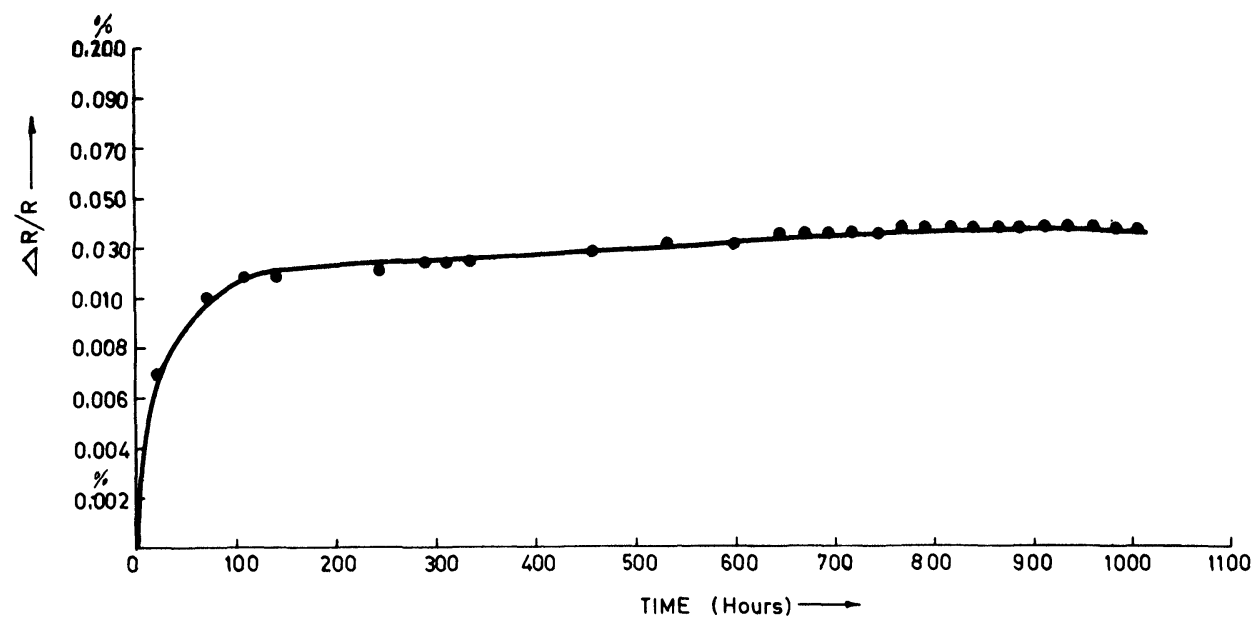

FIGURE 6 Percentage change in the resistance of quartz passivated $\mathrm{NiCr} / \mathrm{Cu}$ resistors measured as a function of time at $70^{\circ} \mathrm{C}$. 


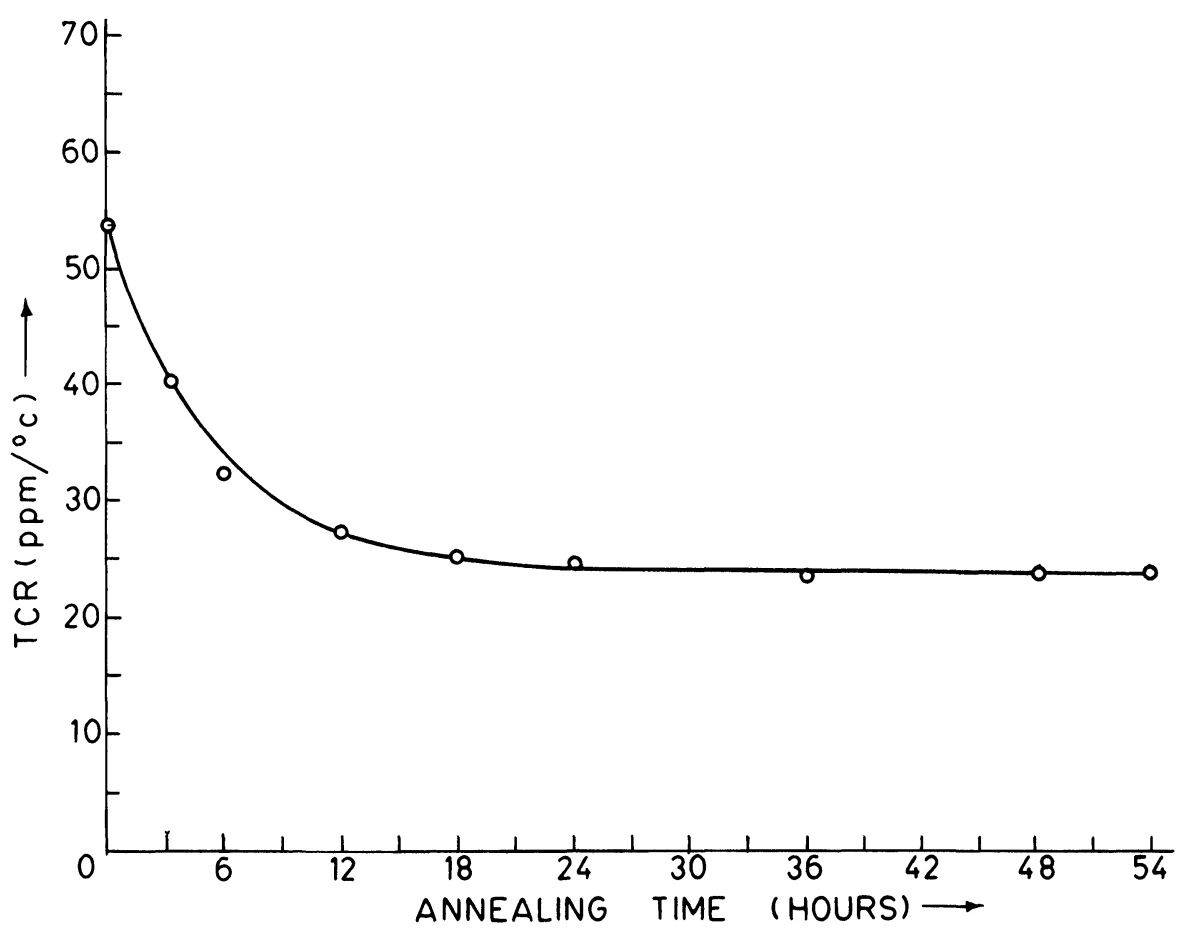

FIGURE 7 TCR of the $\mathrm{NiCr} / \mathrm{Cu}$ resistors measured as a function of annealing time.

TABLE II

Electrical Properties of $\mathrm{NiCr} / \mathrm{Cu}$ Resistors:

\begin{tabular}{lll}
\hline Property & Heat treated resistors & $\begin{array}{l}\text { Heat treated and quartz } \\
\text { passivated resistors }\end{array}$ \\
\hline 1. $\begin{array}{l}\text { Contact I-V } \\
\text { characteristics }\end{array}$ & Ohmic & Ohmic \\
2. $\quad \begin{array}{l}\text { Contact resistance } \\
\left(\mathrm{m} \text { Ohm } \mathrm{Cm}^{2}\right)\end{array}$ & $2-3$ & 3.5 \\
3. $\quad \begin{array}{l}\text { Change in the as prepared } \\
\text { film resistance (\%) }\end{array}$ & 20 & 20 \\
4. Resistor stability after & 0.15 & 0.01 \\
$\begin{array}{l}1000 \text { hours at room } \\
\text { temperature }(\%)\end{array}$ & 0.35 & 0.04 \\
5. Resistor stability after \\
$\begin{array}{l}1000 \text { hours at } 70^{\circ} \mathrm{C}(\%) \\
\left.\text { TCR (ppm } /{ }^{\circ} \mathrm{C}\right)\end{array}$ & 25 & 25 \\
\hline
\end{tabular}

improves significantly after passivation by a thin quartz film. The result of our investigation are summarized in Table II. 


\section{ACKNOWLEDGEMENT}

The authors wish to thank Dr. B.R. Marathe and Prof. H.L. Hartnagel for fruitful discussions.

\section{REFERENCES}

1. L.I. Maissel and R. Glang, 'Hand Book of Thin Films Technology', New York, McGraw Hill, 1970, Ch. 18.

2. P.L. Kirby, 'Applications of Resistive Thin Films in Electronics', Thin Solid Films, Vol. 50, pp 211-221, 1978.

3. I. Johansen et al., 'Examples of Thin Film Applications in Electronic Devices', Thin Solid Films, Vol. 50, pp 171-185, 1978.

4. W.R. Hardy and D.K. Murti, 'Electrical and Structural Properties of NiCr Thin Film Resistors Reactively Sputtered in $\mathrm{O}_{2}$ ", Thin Solid Films, Vol. 20, pp 345-362, 1974.

5. L. Lassak and K. Hieber, 'Structural and Electrical properties of Evaporated $\mathrm{Cr} / \mathrm{Ni}$ Films as a Function of Gas Pressure', Thin Solid Films, Vol. 17, pp 105-111, 1973.

6. J.H. Mooij and M. de Jong, 'Structural and Electrical Properties of sputtered Cr-Ni Films', J. Vac. Sci. and Technology, Vol. 9, pp 446-449, 1972.

7. R.A. Thiel and E.M. Maures, 'TCR control of NiCr Resistors', IEEE Trans. on Components, Hybrids and Manuf. Technology, Vol. CHMT-2 pp 467-475, 1979.

8. J. Rölke, 'Nichrome Thin Film Technology and its application', Proc. International Microelectronics conference, Tokyo, 1980, pp 12-19.

9. R. Tauzes, E. Kansky and A. Banovec, 'The Evaluation of Technology for Depositing NiCr Resistive Films, Thin Solid Films, Vol. 36, pp 379-382, 1976.

10. G. Krüger, 'Applications of Thin Films in Commercial Electronics,' Thin Solid Films, Vol. 12, pp 335-339, 1972.

11. G. Zinsmester, 'Materials and Applications for Thin Films in Hybrid Microelectronics', Electrocomponent Sci and Technology, Vol. 6, pp 209-214, 1980.

12. N.G. Dhere and D.G. Vaiude, "Composition and Temperature coefficient of Resistance of $\mathrm{NiCr}$ Thin Films', Thin Solid Films, Vol. 59, pp 33-41, 1979.

13. G. Nocerino and K.E. Singer, 'Resistance Stabilization of $\mathrm{NiCr}$ by Surface Oxidation', J. Vac. Sci. and Technology, Vol. 16, pp 147-150, 1979.

14. D.S. Campbell and B. Hendry, 'The Effect of Composition on the TCR of NiCr Films, 'Brit. J. of Appl. Phys., Vol. 16, pp 1719-1725, 1965.

15. K.H. Houska, 'Foil Circuits,' Electrocomponent Sci. and Technology, Vol. 7, pp 143-147, 1980.

16. J.S. Fisher and P.M. Hall, 'Termination Materials for Thin Film Resistors', Proc. IEEE, Vol. 59, pp 1418-1424, 1971.

17. J.M. Morabito, J.H. Thomas and N.G. Lesh, 'Material Characterization of Ti-Cu-Ni-Au (TCNA) A new low cost thin film conductor system', IEEE Trans. Parts, Hybrids and Packaging, Vol. PHP 11, pp 253-363, 1975.

18. J.J. O'Neill Jr. and J.L. Vossen, ' $\mathrm{Cr}-\mathrm{Cu}$ and $\mathrm{Cr}-\mathrm{Cu}-\mathrm{Cr}$ Thin Film Metallization', J. Vac. Sci. and Technology, Vol. 10, pp 533-538, 1973.

19. R.K. Nahar, V.K. Khanna and B.R. Marathe, 'Contact Resistance Characteristics of Low Cost $\mathrm{Cu} / \mathrm{NiCr}$ Thin Film Resistor System, Thin Solid Films, Vol. 78, pp 147-152, 1982.

20. P.M. Hall and J.M. Morabito, 'Recent Advances in Solder Bond Technology for Microelectronic Packaging', Thin Solid Films, Vol. 72, pp 433-442, 1980.

21. A. Butts, 'Copper', New York, Reinhold, 1954, Ch. 20. 

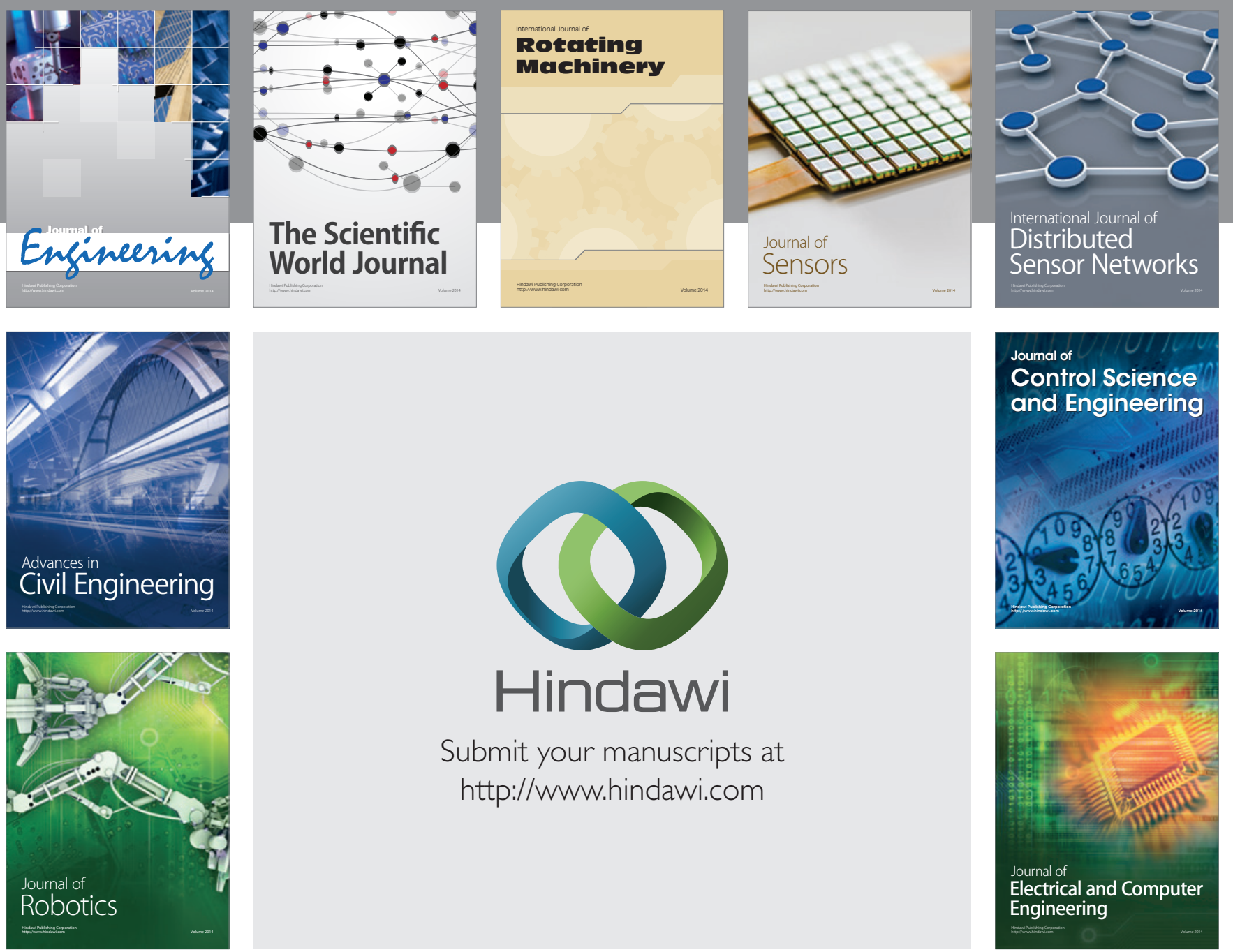

Submit your manuscripts at

http://www.hindawi.com
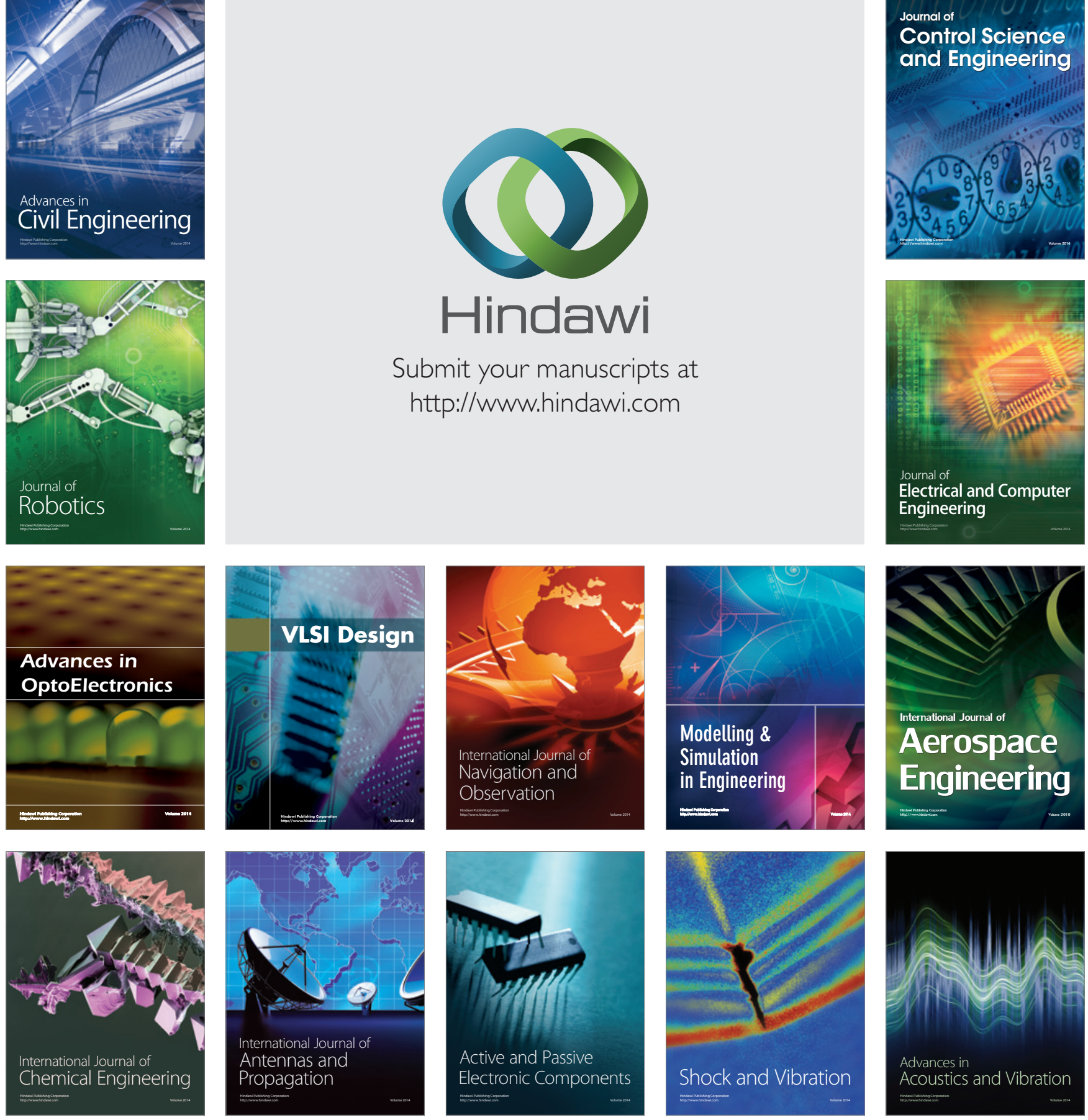